\title{
A study on the electrocardiography in dogs: Reference values and their comparison among breeds, sex, and age groups
}

\author{
Joydip Mukherjee D, Smruti Smita Mohapatra (D), Sonali Jana(D), Pradip Kumar Das (D), Prabal Ranjan Ghosh (D), \\ Kinsuk Das (D) and Dipak Banerjee (i)
}

\begin{abstract}
Department of Veterinary Physiology, Faculty of Veterinary and Animal Sciences, West Bengal University of Animal and Fishery Sciences, Kolkata, West Bengal, India.

Corresponding author: Joydip Mukherjee, e-mail: joyphy@gmail.com

Co-authors: SSM: simplysmruti@gmail.com, SJ: doctorsonaleejanaa@gmail.com, PKD: pkdaskol@rediffmail.com, PRG: drprghosh@gmail.com, KD: kin.suk@hotmail.com,DB: dipakndri@gmail.com

Received: 15-05-2020, Accepted: 16-09-2020, Published online: 23-10-2020
\end{abstract}

doi: www.doi.org/10.14202/vetworld.2020.2216-2220 How to cite this article: Mukherjee J, Mohapatra SS, Jana S, Das PK, Ghosh PR, Das K, Banerjee D (2020) A study on the electrocardiography in dogs: Reference values and their comparison among breeds, sex, and age groups, Veterinary World, 13(10): 2216-2220.

\begin{abstract}
Aim: The present investigation was intended to generate some basic data on electrocardiography (ECG) parameters in different breeds and their alterations in respect to sex and age.

Materials and Methods: The present investigation was carried out on 239 owned dogs of 11 different breeds presented to the Institute Veterinary Clinic during 2018-2019. The animals, irrespective of breed and sex were grouped on the basis of their age groups. Recordings of ECG were performed by a single-channel ECG machine (CardiartR, BPL, India) at $25 \mathrm{~mm} / \mathrm{s}$ paper speed and $10 \mathrm{~mm}=1 \mathrm{mV}$ calibration keeping the animals on the right lateral recumbence without any anesthesia. Heart rate, along with the amplitude and duration of different waves and complexes was measured.

Results: Heart rate did not vary significantly among breeds, sex, and different age groups. The highest heart rate has been reported in Doberman and the lowest in Beagle. The heart rate was lowest at the age group of 6 months- 2.5 years and highest around 10.5-12.5 years irrespective of breed and sex. The incidence of sinus arrhythmia was mostly seen in older dogs. All the waves and complexes did not vary significantly between breeds, age, and sex except P duration which was significantly $(\mathrm{p}<0.05)$ higher in Golden retriever and Doberman breeds.
\end{abstract}

Conclusion: The present investigation generated some reference values of ECG in dogs which will help the clinicians to diagnose different cardiac abnormalities through ECG.

Keywords: dogs, electrocardiogram, heart rate, rhythm.

\section{Introduction}

Cardiac diseases, a silent killer, are common in dogs. The reports of American Veterinary Medical Association stated that 1 in 10 dogs suffer from cardiac diseases [1]. In India, the prevalence rate of cardiac diseases in canines is also increasing at in fast rate [2]. Routine monitoring of cardiac functions is, therefore, an essential prerequisite for early diagnosis of cardiac abnormalities. Electrocardiography (ECG), a non-invasive and inexpensive techniques, is widely employed for the determination of heart rate, heart rhythm, conduction integrity, and mean electrical axis together with myocardial and pericardial affections along with monitoring certain non-cardiac abnormalities such as electrolyte imbalance, drug toxicity, and hormonal disturbances $[3,4]$.

Scanty literatures are available on the ECG in pets in India compared to other developed countries $[5,6]$. Incidence and risk assessment of cardiac arrhythmias

Copyright: Mukherjee, et al. Open Access. This article is distributed under the terms of the Creative Commons Attribution 4.0 International License (http://creativecommons.org/licenses/ by/4.0/), which permits unrestricted use, distribution, and reproduction in any medium, provided you give appropriate credit to the original author(s) and the source, provide a link to the Creative Commons license, and indicate if changes were made. The Creative Commons Public Domain Dedication waiver (http:// creativecommons.org/publicdomain/zero/1.0/) applies to the data made available in this article, unless otherwise stated. in 374 dogs of 15 different breeds with respect to age, breed, and sex and associated biochemical changes were carried out by Kumar et al. [7]. Gugjoo et al. [8] reported reference values of six limb lead ECG in 24 healthy conscious Labrador Retriever dogs. We, while, investigating the ECG pattern of three exotic breeds of trained dogs [9], encountered difficulties due to lack of appropriate reference values based on a large number of dog populations in respect to breed, sex, age, and other physiological states for accurate interpretation and appropriate therapeutic interventions [10].

Therefore, the present investigation was intended to generate some basic data on ECG parameters based on 239 dogs of 11 different breeds in respect to sex and age. Breed- and age-wise incidence of different cardiac abnormalities was also discussed.

\section{Materials and Methods}

\section{Ethical approval}

The experiments on animals including all procedures of this study were approved by Institutional Animal Ethics Committee (Registration number: 763/03/a/CPCSEA).

\section{Study location, period and clinical subjects}

The present investigation was carried out on the 239 owned dog patients presented to the Veterinary 
Clinic under West Bengal University of Animal and Fishery Sciences, Kolkata, West Bengal, India, during 2018-2019 by the clients. There were 11 different breeds, namely, Mongrel ( $\mathrm{n}=21)$, Labrador Retriever $(\mathrm{n}=26)$, crossbred $(\mathrm{n}=25)$, Spitz $(\mathrm{n}=22)$, Beagle $(\mathrm{n}=17)$, Pug $(\mathrm{n}=29)$, Dachshund $(\mathrm{n}=15)$, German Shepherd $\operatorname{dog}(n=24)$, Pomeranian $(n=26)$, Golden Retriever $(\mathrm{n}=20)$, and Doberman $(\mathrm{n}=14)$. The average age was 6.9 years. Out of the total studied dogs, $42.86 \%(n=103)$ were male and $57.14 \%(n=136)$ were female. The animals irrespective of breed and sex were grouped on the basis of their age into below 6 months $(\mathrm{n}=18), 6$ months -2.5 years $(\mathrm{n}=35), 2.5$ years -4.5 years $(\mathrm{n}=34), 4.5$ years- 6.5 years $(\mathrm{n}=33), 6.5$ years- 8.5 years $((\mathrm{n}=36), 8.5$ years-10.5 years $(\mathrm{n}=37), 10.5$ years- 12.5 years $(\mathrm{n}=25)$, and 12.5 years- 15 years $(\mathrm{n}=21)$.

\section{Recording of ECG}

Recordings of ECG were performed by a single-channel ECG machine (CardiartR, BPL, India) at $25 \mathrm{~mm} / \mathrm{s}$ paper speed and $10 \mathrm{~mm}=1 \mathrm{mV}$ calibration keeping the animals on the right lateral recumbence without any anesthesia. All the recordings of standard bipolar limb leads (I, II, and III) and unipolar augmented limb leads (aVR, aVL, and aVF) were taken on thermosensitive ECG paper (CardiartR) having width of $50 \mathrm{~cm}$ and recording width of $40 \mathrm{~mm}$. Each small square on horizontal axis represents $0.04 \mathrm{sec}-$ ond and on vertical axis represents 0.1 millivolt $(\mathrm{mV})$. Amplitude of P, Q, R, S, and T waves was measured together with PR interval, QRS interval in lead II as its electrode direction matched the typical waves as the depolarization vector [11].

\section{Measurement of heart rate, complexes, and intervals of ECG}

Waves and complexes of lead-II were used as typical waves to calculate amplitude and durations of different waves and complexes as the depolarization vector is directed toward the electrode of lead-II [11]. Amplitude and duration of $\mathrm{P}, \mathrm{Q}, \mathrm{R}, \mathrm{S}$, and $\mathrm{T}$ waves were measured together with PR interval, QRS interval, and QT interval. Heart rate was calculated by successive R-R interval.

\section{Statistical analysis}

Three-way analysis of variance was used to test the significance among breeds, age groups, and sex by SPSS software version 15.0 (SPSS, Inc., Chicago, IL, USA).

\section{Results and discussion}

\section{Heart rate}

The heart rate (bpm) in different breeds of dogs is presented in Table-1. No significant differences between different breeds of dogs in respect to heart rate were found though the highest heart rate $(150.00 \pm 18.24)$ has been observed in Doberman and

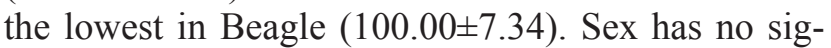
nificant effect on the heart rate, irrespective of age and breeds. The heart rate was lowest at the age group of 6 months-2.5 years and highest around 10.5-12.5 years irrespective of breed and sex.

The variation of heart rate in different breeds of dogs obtained in this investigation may occur due to several factors such as exercise, age, breed, body condition score, motor activity, and sleep [12]. We found slightly lower values in Beagle when compared to that of Hanton and Rabemampianina [13], in the same breed of dogs. The heart rate of GSD obtained in this study was corroborated with the earlier reports of Rezakhani et al. [14] but higher than trained GSD reported by Mukherjee et al. [9]. The Labrador breeds were exhibiting higher heart rate in this study than the earlier report [8]. The heart rate of Mongrels was within the range as reported by Schneider et al. [15]. The variability in the heart rates has been studied earlier among different breeds such as Doberman [16], Spaniels [17], and Beagles [18], both in clinically healthy and diseased model. However, most of the studies considered a single breed rather than comparing different breeds of dogs. In one of our previous investigations [9], we compared the heart rates in trained Labrador, German Shepherd, and Golden Retriever dogs used in police dog squad. In comparison with these data with the present investigation, it was depicted that trained dogs exhibited lower heart rates compared to normal dogs of the same breeds. In a related study, Doxey and Boswood [19] compared GSD, Labrador, Cocker Spaniels, Boxer, Bulldog, and Cavalier King Charles spaniels for heart rate variation and found no significant differences among breeds.

\section{Heart rhythm}

The majority of dogs under study were exhibited normal sinus rhythm (25.40\%). The incidence of sinus arrhythmia was $15.87 \%$ which was mostly common in older dogs (10.5-12.5 years). Spitz breeds were most susceptible to sinus arrhythmia depicted in this study. Sinus tachycardia was found in $17.46 \%$ of dogs under investigation of which Labrador and Spitz were most susceptible and its incidence was maximum in the age group of 2.5-4.5 years and 6.5-8.5 years. The incidence of bradycardia was less $(3.17 \%)$ with the maximum occurrence in Spitz.

The overall incidence of arrhythmia depicted in the present investigation was slightly lower than the earlier reports of Kumar et al. [7] (21.92\%) and higher than the reports of Sarita [20] (7.67\%). The highest incidences of cardiac arrhythmias were reported in Pomeranian [7,20] but, in our investigation, we found that the incidence was highest in Spitz and Labrador. This could be probably due to less number of observations $(2 \%)$ in this breed during investigation. The age-wise incidence of cardiac arrhythmias was in accordance with the earlier observation [21] reported a higher incidence of cardiac arrhythmias in pups and older dogs.

\section{Waves and complexes of ECG}

The values of different waves and complexes of ECG in different breeds, age groups, and sex are 


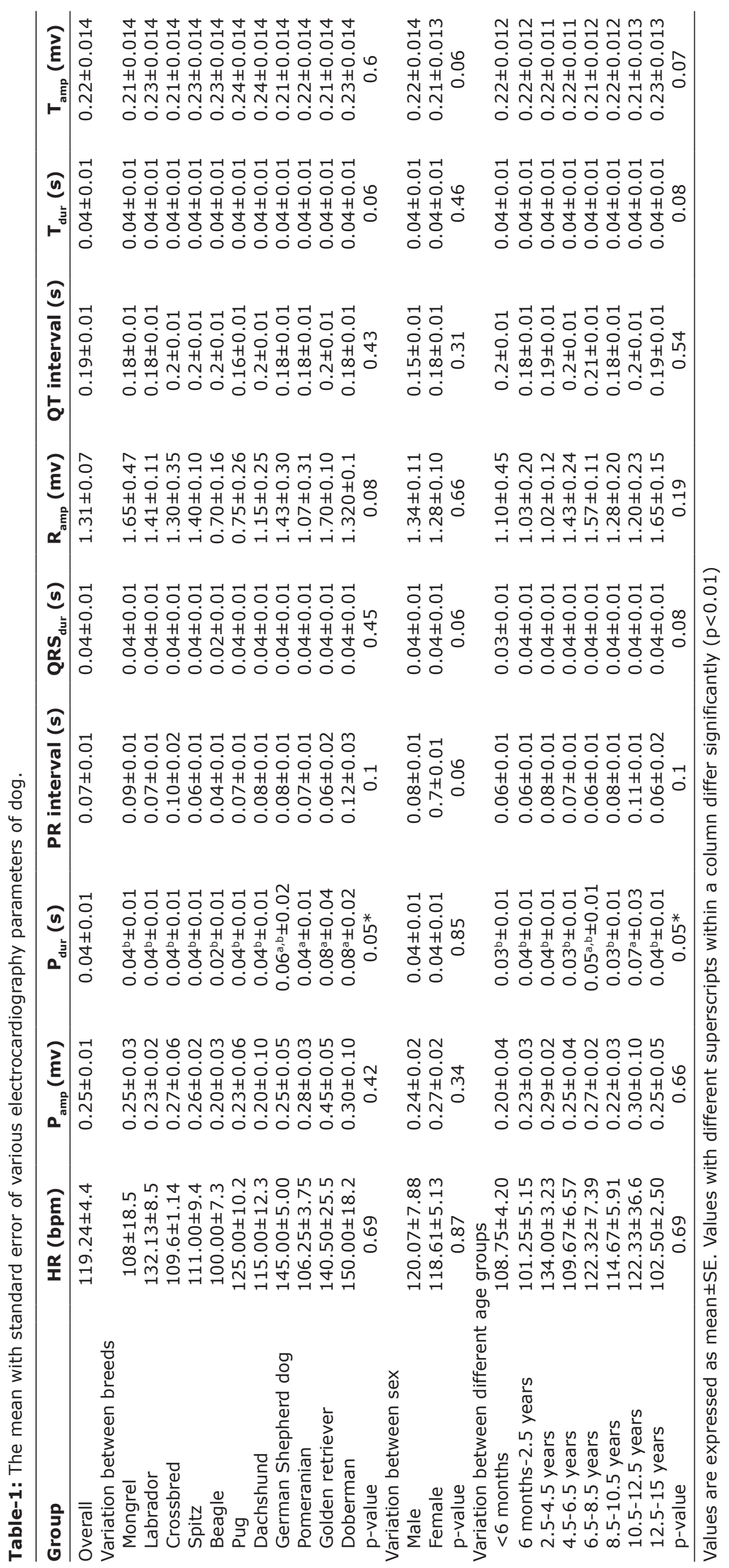


presented in Table-1. In this investigation, measurements of waves and complexes were made from lead-II as it is directed toward the electrode of lead II and considered as waves of typical depolarization vector $[9,10]$. We did not get any significant variation ( $p>0.05)$ between breeds, age, and sex in the amplitude of $\mathrm{P}$ wave, the first positive wave denoting atrial depolarization in lead-I, II, III, and aVF though significant variations $(p<0.05)$ found in $P$ wave duration between different breeds and different age groups. We found no significant differences $(p>0.05)$ between breed and age groups in our previous study [9] on the trained breed of dogs. The values of $\mathrm{P}$ wave amplitude were in accordance with the earlier reports of Burman et al. [22] but higher than the other reports $[8,9,23]$. On breed-wise comparison, the values were similar for earlier reports in Beagle [13] and Labrador, but the values for Golden Retriever were lower than the earlier reports [9] and the values were higher for GSD compared to the earlier studies $[9,14]$. The variation in the $\mathrm{P}$ wave amplitude may be in response to heart rate and stress [8]. The sex has no effect on $\mathrm{P}$ wave configuration as corroborated by the earlier studies [13]. On contrary, Upeniece [24] showed that P waves in lead-I and aVF were correlated with sex and body weight. The obtained values of PR interval representing the nodal delay and the time required for the electrical impulses to travel from SA node to AV node were supported by earlier works $[9,25]$.

The $\mathrm{Q}$ wave is the first negative deflection in lead-II and represents the electrical transmission into intraventricular septum. Earlier report [22] showed the presence of Q wave in lead I, II, III, and aVF and absence in lead aVR and aVL. However, in contrary, Avizeh et al. [22] and Bernal et al. [26] reported the presence of Q wave in all the leads. We also found Q waves in all the leads without any significant variation in the amplitude between breeds, age, and sex. Bernal et al. [26] also reported a non-significant difference between sex and body weight. However, Sato et al. [27] reported that altered Q wave amplitude between different breeds may be associated with thoracic peculiarities of different dogs.

In the present study, QRS duration representing ventricular depolarization in the dogs, the increase of which is indicative of ventricular enlargement [25] was similar between breeds, sex, and age groups and in accordance with the earlier reports $[9,21]$.

The $\mathrm{R}$ wave represents the depolarization of major ventricular muscles and used to diagnose the left ventricular function [25]. In our current investigation, $\mathrm{R}$ wave did not vary significantly between breeds, but non-significant higher values were obtained in Labrador, GSD, Mongrels, and Doberman compared to small breeds. Earlier reports [25] also stated higher $\mathrm{R}$ wave amplitude in large breeds of dogs due to increased ventricular surface area and thickened wall in large breeds compared to smaller ones.
The QT intervals obtained in this investigation were in accordance with the earlier reports $[8,9]$. Normally QT interval is the representative of ventricular systole and it is the summation of ventricular depolarization and repolarization [23]. QT interval varied between wide range and under the influence of catecholamines and vagal activity [23], but, in this investigation, there were no significant differences between different breeds, sex, and age groups.

The repolarization of ventricular myocardium can be represented in T wave and normally it should be less than one-fourth amplitude of $\mathrm{R}$ wave [25]. $\mathrm{T}$ wave amplitude and duration obtained in this investigation were in accordance with the earlier reports $[8,27]$ but lower than the reports of Gugjoo et al. [8]. In this investigation, $44 \%$ of dogs exhibited positive T wave and $56 \%$ of dogs appeared with inverted $\mathrm{T}$ wave. The reasons for altered polarity of $\mathrm{T}$ wave were not fully understood $[28,29]$, but some authors suggested that the elevation of diaphragm during respiration could be one of the probable reasons behind the altered polarity of $\mathrm{T}$ wave in lead-II [7]. Breed-wise variations in the T wave polarity have also been documented in our previous study [9]. In some dogs, ventricular repolarization occurs in the same direction as depolarization, from inside the ventricles (endocardium) to outside (epicardium). This repolarization pattern generates a negative voltage in the left chest member, compared to the right chest member, forming a deflection of the negative $\mathrm{T}$ wave [30].

\section{Conclusion}

The present investigation generates some basic data on canine electrocardiographic patterns in different breeds which expand the existing knowledge to help the clinicians for monitoring cardiac abnormalities in different breeds and different age groups.

\section{Authors' Contributions}

JM planned the study. SSM, SJ, JM, DB, and $\mathrm{KD}$ recorded the data. $\mathrm{PKD}$ analyzed the data. JM and PRG drafted and revised the manuscript. All authors read and approved the final manuscript.

\section{Acknowledgments}

The authors are highly thankful to the honorable Vice-Chancellor, West Bengal University of Animal and Fishery Sciences, for providing necessary facilities and financial support (ICAR Development Grant 2018-19 Sub Head 7.2 (No. VCS/WBUAFS/1-18(PtIII)/131(5)/4 dt. 10.10.2018) to carry out this work.

\section{Competing Interests}

The authors declare that they have no competing interests.

\section{Publisher's Note}

Veterinary World remains neutral with regard to jurisdictional claims in published institutional affiliation. 


\section{References}

1. Schrope, D.P. (2015) Prevalence of congenital heart disease in 76, 301 mixed-breed dogs and 57, 025 mixed-breed cats. J. Vet. Cardiol., 17(3): 192-202.

2. Reetu, Hoque, M., Saxena, A.C., Pawde, A.M., Verma, N.K., Kalaiselvan, P. and Dey, S. (2017) Incidence of cardiac diseases in dogs: A retrospective study. Indian J. Vet. Med., 37(1-2): 64-67.

3. Baisan, R.A., Rosa, A.D., Loria, A.D., Vulpe, V. and Pinantedosi, D. (2016) Cardiac biomarkers in clinical practice in dogs and cat-a review. Hum. Vet. Med., 6(1): 51-58.

4. Bodh, D., Hoque, M., Saxena, A.C., Gugjoo, M.B. and Bist, D. (2016) Diagnosis of dilated cardiomyopathy and pericardial effusion in two dogs. Indian J. Vet. Surg., 37(1): 48-50.

5. Thirunavukkarasu, P. (2019) Prevalence of canine acquired heart diseases in Chennai, India. Int. J. Livest. Res., 9(3): 331-339.

6. Gupta, D.K., Singh, J.L. and Kumar, M. (2007) Clinicopathological changes in cardiac arrhythmia in dogs. Indian J. Vet. Med., 27: 91-94.

7. Kumar, A., Dey, S. and Mahajan, S. (2014) Incidence and risk assessment of cardiac arrhythmias in dogs with respect to age, breed, sex and associated biochemical changes. $A d v$. Anim. Vet. Sci., 2(5): 277-281.

8. Gugjoo, M.B., Hoque, M., Saxena, A.C. and Zama, M.M.S. (2014) Reference values of six-limb-lead electrocardiogram in conscious Labrador retriever dogs. Pak. J. Biol. Sci., 17(5): 689-695.

9. Mukherjee, J., Das, P.K., Ghosh, P.R., Banerjee, D., Sharma, T., Basak, D. and Sanyal, S. (2015) Electrocardiogram pattern of some exotic breeds of trained dogs: A variation study. Vet. World, 8(11): 1317-1320.

10. Hoque, M., Saxena, A.C., Reetu, Gugjoo, M.B. and Bodh, D. (2019) Cardiac diseases in dogs. Indian J. Anim. Health, 58(1): 1-20.

11. Okutucu, S. and Oto, A. (2018) Fundamentals of ECG. In: Interpreting ECGs in Clinical Practice. In Clinical Practice. Springer, Cham.

12. Schreiner, P.J. (2016) Emerging cardiovascular risk research: Impact of pets on cardiovascular risk prevention. Curr. Cardiovasc. Risk Rep., 10(2): 8.

13. Hanton, G. and Rabemampianina, Y. (2006) The electrocardiogram of the Beagle dog: Reference values and effect of sex, genetic strain, body position and heart rate. Lab. Anim., 40(2): 123-136

14. Rezakhani, A., Atwell, R.B. and Webster, J. (1990) Electrocardiographic values of German shepherd dogs. Aust. Vet. J., 67(8): 307-309.

15. Schneider, H.P., Truex, R.C. and Knowles, J.O. (1964) Comparative observations of the hearts of mongrel and Greyhound dogs. Anat. Rec., 149(2): 173-179.

16. Calvert, C.A. and Wall, M. (2001) Effect of severity of myocardial failure on heart rate variability in doberman pinschers with and without echocardiographic evidence of dilated cardiomyopathy. J. Am. Vet. Med. Assoc., 219(8): 1084-1088.

17. Haggstrom, J., Hamlin, R.L., Hansson, K. and Kvart, C. (1996) Heart rate variability in relation to severity of mitral regurgitation in cavalier King Charles spaniels. J. Small Anim. Pract., 37(2): 69-75.

18. Eaton, G.M., Cody, R.J., Nunziata, E. and Binkley, P.F. (1995) Early left ventricular dysfunction elicits activation of sympathetic drive and attenuation of parasympathetic tone in the paced canine model of congestive heart failure. Circulation, 92(3): 555-561.

19. Doxey, S. and Boswood, A. (2004) Differences between breeds of $\mathrm{dog}$ in a measure of heart rate variability. Vet. Rec., 154(23): 713-717.

20. Sarita, D. (2008) Epidemiological Studies of Canine Cardiac Diseases Including Clinicopathology, Diagnosis and Therapeutic, M.V.Sc., Thesis. Anand Agriculture University, Gujarat, India.

21. Changkija, B. (2000) Electrocardiographic Studies in Dogs with Reference to Management of Cardiac Tachyarrhythmia by Alternative Drugs. Ph.D., Thesis. Indian Veterinary Research Institute, Izatnagar, Uttar Pradesh, India.

22. Burman, S.O., Kahn, S. and Panagopoulos, P. (1966) The electrocardiogram of the normal dog. J. Thorac. Cardiovasc. Surg., 51(3): 379-382.

23. Avizeh, R., Papahn, A.A., Ranjbar, R., Rasekh, A.R. and Molaee, R. (2010) Electrocardiographic changes in the littermate mongrel dogs from birth to six months of life. Iran. J. Vet. Res., 11(433): 304-310.

24. Upeniece, D. (2004) Electrocardio Physiological Parameters of the Cocker Spaniel Rottweiler and German Shepherd Dogs, Ph.D., Thesis. Latvia University of Agriculture, Faculty of Veterinary Medicine Preclinical Institute, Jelgava.

25. Tilley, L.P. (1992) Essentials of canine and feline electrocardiography. In: Cann, C.C., editor. Interpretation and Treatment. Vol. 3. Lea and Febiger, Philadelphia, PA.

26. Bernal, L.J., Montes, A.M., Del Palacio, M.J.F. and Parrizo, C.G. (1995) Electrocardiographic changes in the growing Mastin Espanol. J. Small Anim. Pract., 36(5): 221-228.

27. Sato, H., Fujii, Y. and Wakao, Y. (2000) Standard electrocardiographic values in normal retrievers. Adv. Anim. Cardiol., 33(1): 11-15.

28. Su, W.L., Too, K., Wang, M.H., Jiang, Y.N. and Pan, M.J. (2001) Reference values of six-limb-lead ECG in conscious Taiwanese dogs. Adv. Anim. Cardiol., 35(2): 86-95.

29. van Oosterom, A. (2001) Genesis of the T wave as based on an equivalent surface source model. J. Electrocardiol., 34(Suppl): 217-227.

30. Klein, L.R., Shroff, G.R., Beeman, W. and Smith, S.W. (2015) Electrocardiographic criteria to differentiate acute anterior ST-elevation myocardial infarction from left ventricular aneurysm. Am. J. Emerg. Med., 33(6): 786-790. 